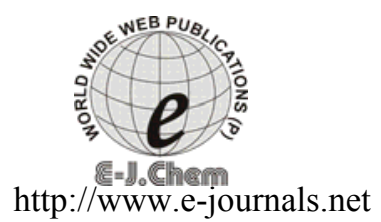

\title{
Validated Reverse Phase HPLC Method for the Determination of Impurities in Etoricoxib
}

\author{
S.VENUGOPAL ${ }^{\S^{*}}$, U.M.TRIPATHI and N.DEVANNA ${ }^{\S}$ \\ *Analytical Research \& Development \\ Vindhya Organics Pvt. Ltd, Plot No.3, 4 \& 5 \\ IDA Bollaram, Medak -502325, A.P., India \\ Startech Labs Pvt Ltd, Madinaguda, Hyderabad-500055, A.P., India \\ ${ }^{\S}$ Department of Chemistry, JNTU, Anantapur-515002, A.P., India \\ venugopalsriram23@gmail.com
}

Received 1 March 2011; Accepted 27 April 2011

\begin{abstract}
This paper describes the development of reverse phase HPLC method for etoricoxib in the presence of impurities and degradation products generated from the forced degradation studies. The drug substance was subjected to stress conditions of hydrolysis, oxidation, photolysis and thermal degradation. The degradation of etoricoxib was observed under base and oxidation environment. The drug was found stable in other stress conditions studied. Successful separation of the drug from the process related impurities and degradation products were achieved on zorbax SB CN $(250 \times 4.6 \mathrm{~mm}) 5 \mu \mathrm{m}$ particle size column using reverse phase HPLC method. The isocratic method employed with a mixture of buffer and acetonitrile in a ratio of 60:40 respectively. Disodium hydrogen orthophosphate $(0.02 \mathrm{M})$ is used as buffer and $\mathrm{pH}$ adjusted to 7.20 with $1 \mathrm{~N}$ sodium hydroxide solution. The HPLC method was developed and validated with respect to linearity, accuracy, precision, specificity and ruggedness.
\end{abstract}

Key words: RP-HPLC, Etoricoxib, Impurities, Validation

\section{Introduction}

Etoricoxib (Figure 1), the active ingredient in Arcoxia $^{1}$, is a COX-2 inhibitor and is used in the treatment of osteoarthritis and rheumatoid arthritis. Etoricoxib inhibits the second isoform of cyclooxygenases enzyme (COX-2). Since COX-2 is crucial ${ }^{2-6}$ in the production of prostaglandins (the molecules in the body largely responsible for pain, inflammation, and swelling caused by many medical conditions), inhibition of COX-2 effectively decreases pain. 
<smiles>Cc1ccc(-c2ncc(Cl)cc2-c2ccc(S(C)(=O)=O)cc2)cn1</smiles>

Figure 1. Chemical structure of Etoricoxib

(5-Chloro-2-(6-methyl pyridine-3yl) 3-(4-methyl sulfonyl phenyl) pyridine (Etorocoxib))

The different analytical techniques reported ${ }^{7-16}$ so far for the determination of this drug and its simultaneous determination along with other substances are also reported ${ }^{12-16}$. HPLC method was developed for the determination of etoricoxib and the impurities arising during its manufacturing. In the present study, we describe a reverse phase liquid chromatography method for the separation of process and degradation impurities of etoricoxib. The specificity accuracy, linearity, precision, limit of detection (LOD), limit of quantification (LOQ) and robustness of the method were determined in accordance with ICH guidelines ${ }^{17-}$ ${ }^{18}$. This paper reports, a rapid, efficient, simple and validated LC method for the separation of impurities and degradation products.

\section{Experimental}

Etoricoxib sample was provided by the Research division of Vindhya, India. Three impurities namely impurity-A, impurity-B and impurity-C (Figure 2) were procured from the customer. All reagents used were of analytical reagent grade stated otherwise. Milli Q water, HPLC-grade acetonitrile, AR-grade disodium hydrogen orthophosphate were purchased from rankem.<smiles>CS(=O)(=O)c1ccc(CC(=O)O)cc1</smiles>

(4-Methanesulfonyl-phenyl)-acetic acid Impurity-A<smiles>COC(=O)c1ccc(C)nc1</smiles>

2-(4-Methanesulfonyl-phenyl)-1(6-methyl-pyridin-3-yl)-ethanone

Impurity-C

6-Methyl-nicotinic acid methyl ester Impurity-B

Figure 2. Impurities of etoricoxib

The HPLC system was equipped with quaternary gradient pumps with auto sampler and injector (Shimadzu LC 2010, Japan) controlled with LC solutions software (Shimadzu). 


\section{Preparation of standard solution}

Accurately weighed $25 \mathrm{mg}$ of etoricoxib was transferred into a $50 \mathrm{~mL}$ volumetric flask, added about $25 \mathrm{~mL}$ of diluent, sonicated to dissolve and diluted up to the mark with diluent.

\section{Preparation of sample solution}

Accurately weighed $25 \mathrm{mg}$ of etoricoxib sample was transferred into a $50 \mathrm{~mL}$ volumetric flask, added about $25 \mathrm{~mL}$ of diluent, sonicated to dissolve and diluted up to the mark with diluent.

\section{Chromatographic conditions}

The chromatographic separation was achieved on a zorbax SB CN $250 \times 4.6 \mathrm{~mm}, 5 \mu \mathrm{m}$ particle size column. The Isocratic LC method employs with the composition of solution A and $\mathrm{B}$ as mobile phase in the ration of 60:40 respectively. Solution A contains $0.02 \mathrm{M}$ disodium hydrogen orthophosphate $\mathrm{pH}$ adjusted to 7.20 with $1 \mathrm{~N}$ sodium hydroxide solution and Solution B contains HPLC grade acetonitrile. The flow rate of the mobile phase was $0.8 \mathrm{~mL} / \mathrm{min}$ and the peak shape of the Etoricoxib was found to be symmetrical. The detection was performed at UV $\lambda_{235} \mathrm{~nm}$. The injection volume was $10 \mu \mathrm{L}$. A mixture of buffer and acetonitrile (50:50, v/v) was used as a diluent.

\section{Validation of the Method}

\section{Specificity}

Specificity is the ability of the method to measure the analyte response in the presence of its potential impurities. The specificity of the developed LC method for Etoricoxib was carried out in the presence of its impurities namely, impurity-A, impurity-B and impurity-C. Stress studies were performed for etoricoxib drug substance to provide an indication of the stability indicating property and specificity of the proposed method. Degradation study was performed on $0.5 \mathrm{mg} / \mathrm{mL}$ solution of the drug in diluent neutral, acid hydrolysis, base hydrolysis and oxidation was carried out by using diluent, $2 \mathrm{~mL}$ of $1 \mathrm{~N}$ hydrochloric acid, $2 \mathrm{~mL}$ of $1 \mathrm{~N}$ sodium hydroxide and $2 \mathrm{~mL}$ of $50 \%$ hydrogen peroxide solution respectively. These solutions were prepared and each was heated in water bath at $80{ }^{\circ} \mathrm{C}$ for $1 \mathrm{~h}, 2 \mathrm{~h}, 3 \mathrm{~h}$ and $4 \mathrm{~h}$ respectively. Photolytic and thermal degradation was carried out on drug substance by exposing it separately on short wavelength light $(254 \mathrm{~nm})$ and heat $\left(105{ }^{\circ} \mathrm{C}\right)$ for 4 days. Sample were withdrawn at appropriate time and subjected to analysis. All the impurities and degradation products were separated with appropriate resolution by the developed method.

\section{Precision}

The precision of the related substance method was checked by injecting six individual preparations of etoricoxib spiked with $0.5 \%$ of each impurity with respect to the etoricoxib analyte concentration. The \%RSD of the area of each impurity was calculated. The intermediate precision of the method was also evaluated using different analyst and different instrument in the same laboratory.

\section{LOD and $L O Q$}

The LOD and LOQ were determined by measuring the signal to noise ratio of the each substance. The LOD and LOQ for Etoricoxib, impurity-A, impurity-B and impurity-C were determined by injecting a series of dilute solutions with known concentrations. The precision study was also carried out at the LOQ level by injecting six individual preparations of etoricoxib, impurity-A, impurity-B and impurity-C, calculating \%RSD for the areas of each impurity. 


\section{Accuracy}

The accuracy of the method for all the related substances was determined by analyzing Etoricoxib sample solutions spiked with all the related substances at four different concentration levels of LOQ, 50, 100 and $150 \%$ of each in triplicate at the specified limit. The percentage of recoveries for the impurities was calculated by injecting the standard solution for each level.

\section{Linearity}

The Linearity of the method for all the related substances was determined by analyzing dilute solution of Etoricoxib and its related substances at four different concentration levels of LOQ, 50, 100 and $150 \%$ of each in triplicate at the specified limit. The correlation coefficient was calculated for each substance.

\section{Robustness}

To determine the robustness of the developed method, experimental conditions were deliberately altered and the resolution between the etoricoxib, impurity-A, impurity-B and impurity-C was recorded. The parameters selected were mobile phase composition, $\mathrm{pH}$ of the mobile phase ( \pm 0.2 units) and flow rate $( \pm 0.2 \mathrm{~mL} / \mathrm{min})$.

\section{Solution and mobile phase stability}

To determine the stability of sample solution, the sample solutions of Etoricoxib spiked with related substances at specified level were prepared and analyzed immediately after preparation and after different time intervals for $48 \mathrm{~h}$. The results of these study indicated, the sample solution was stable at room temperature for $48 \mathrm{~h}$.

\section{Results and Discussion}

\section{Optimization of chromatographic conditions}

The main objective of the chromatographic method was to separate etoricoxib from impurity-A, impurity-B and impurity-C. Impurities were co-eluted using different stationary phase such as $\mathrm{C} 8$ and $\mathrm{C} 18$ and as well as different mobile phases. During evaluation of different column chemistries, cyano column was observed to give better resolution with the buffer $\mathrm{pH}$ of 7.20. A good resolution and peak shape were optimized as mentioned under section "Chromatographic conditions". In optimized chromatographic conditions etoricoxib, impurity-A, impurity-B and impurity- $\mathrm{C}$ were separated with a good resolution greater than 2 , typical relative retention times for impurity-A, impurity-B and impurity-C were approximately $0.23,0.52$ and 0.63 respectively (Figure 3 ). Specificity details are mentioned in the Table 1.

Table 1. Specificity details

\begin{tabular}{ccccc}
\hline Parameter & Etoricoxib & Impurity-A & Impurity-B & Impurity-C \\
\hline RT & 11.510 & 2.698 & 5.988 & 7.347 \\
RRT & 1.000 & 0.234 & 0.520 & 0.638 \\
N & 12706 & 3524 & 9024 & 9669 \\
TF & 1.082 & 1.345 & 1.180 & 1.087 \\
\hline
\end{tabular}

$R T=$ Retention time, $R R T=$ Relative retention time, $N=$ Theoretical plates $\& T F=$ Tailing factor 


\section{Validation of the method}

\section{Forced degradation}

Degradation was not observed in etoricoxib sample when subjected to stress conditions like neutral, thermal and photolytic. Etoricoxib was degraded under base hydrolysis and oxidation conditions (Figure 4 and 5). The summary of the forced degradation study is mentioned in Table 2.

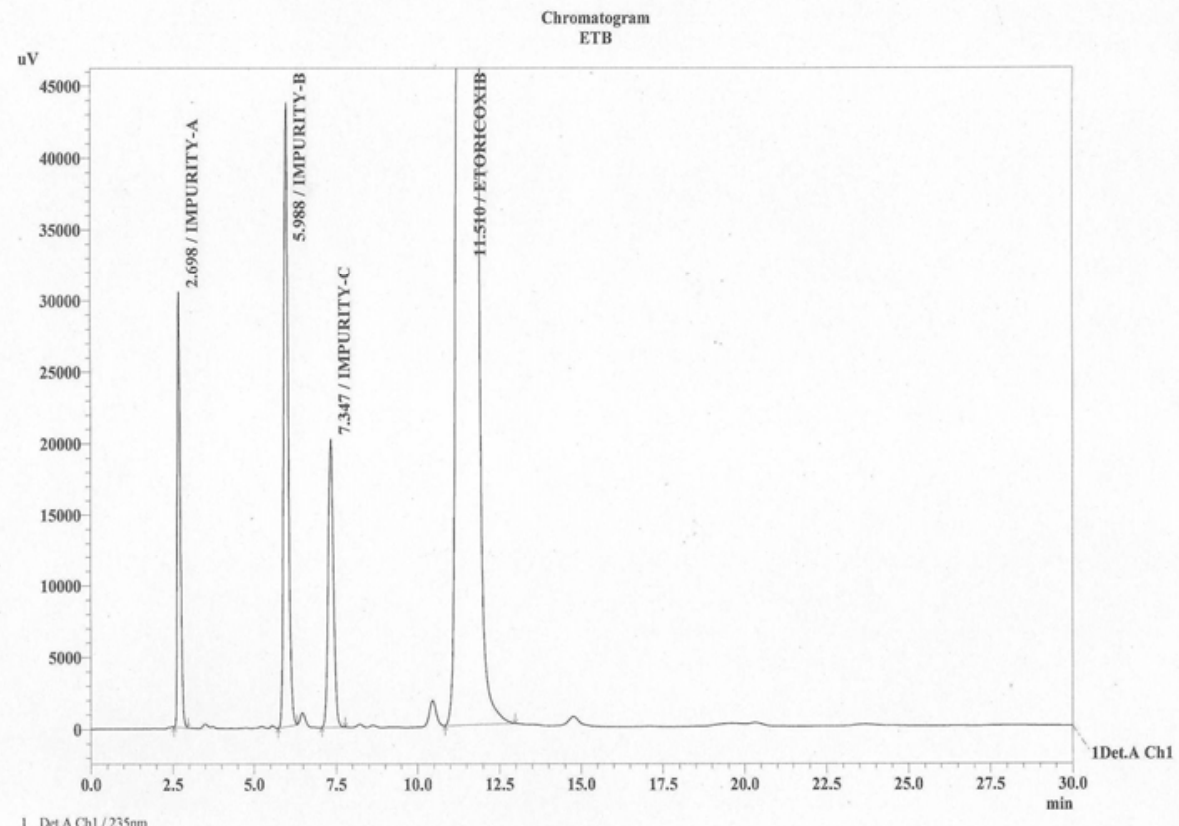

Figure 3. Etoricoxib spiked with all impurities

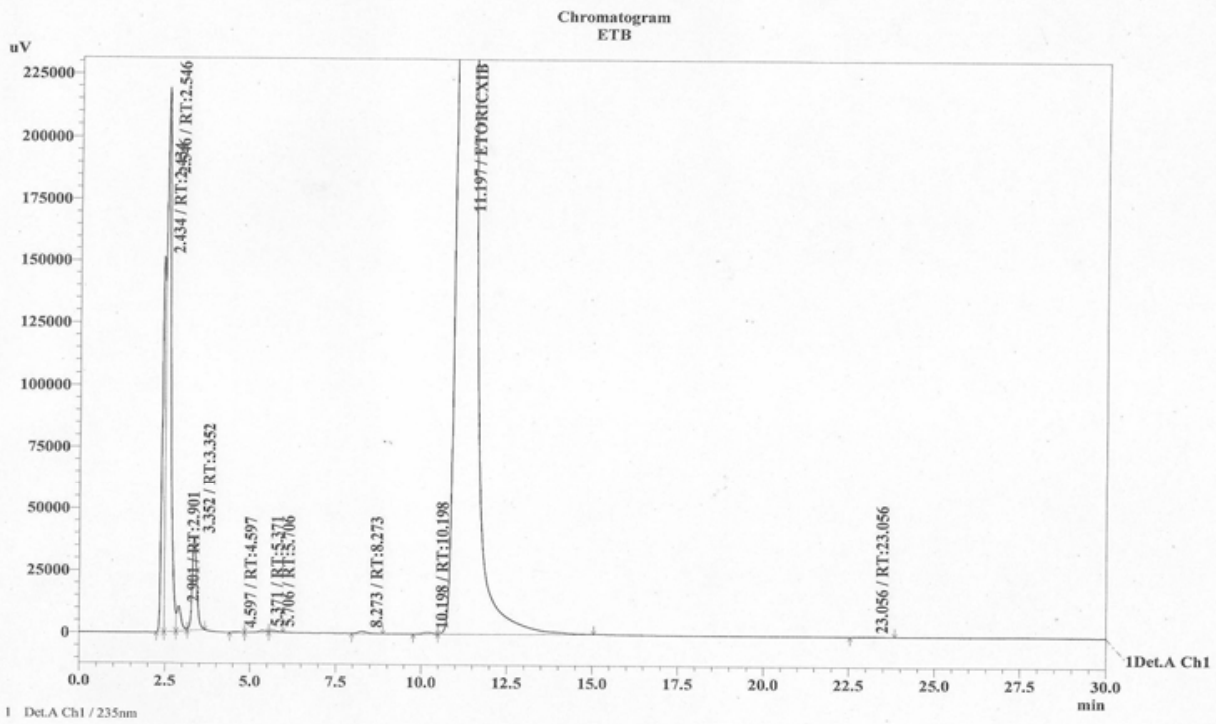

Figure 4. Etoricoxib base degradation sample $2 \mathrm{~mL}$ of $1 \mathrm{~N} \mathrm{NaOH}\left(3 \mathrm{~h}\right.$ at $\left.80^{\circ} \mathrm{C}\right)$ 


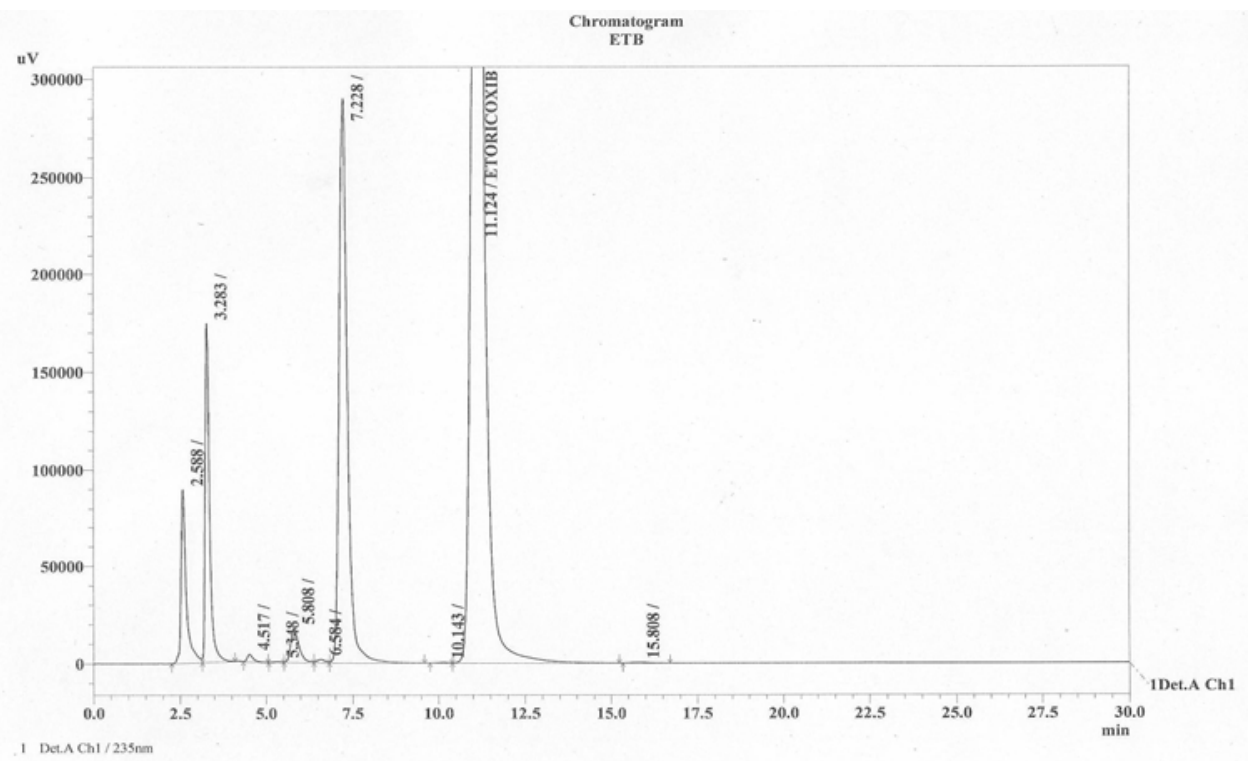

Figure 5. Etoricoxib peroxide degradation sample $2 \mathrm{~mL} 50 \%$ Hydrogen peroxide $\left(1 \mathrm{~h}\right.$ at $\left.80{ }^{\circ} \mathrm{C}\right)$

Table 2. Forced degradation study result of etoricoxib

\begin{tabular}{lcl}
\hline \multicolumn{1}{c}{ Degradation condition } & $\begin{array}{c}\% \\
\text { Purity }\end{array}$ & \multicolumn{1}{c}{$\begin{array}{c}\text { RRT of major degradation } \\
\text { peaks }\end{array}$} \\
\hline $\begin{array}{l}\text { Control sample } \\
\text { Neutral condition }\left(80^{\circ} \mathrm{C}, 4 \mathrm{~h} \text { only diluent) }\right.\end{array}$ & $\begin{array}{c}99.95 \\
\text { Acid hydrolysis }\left(80^{\circ} \mathrm{C}, 4 \mathrm{~h}, 2 \mathrm{~mL}, 1 \mathrm{~N} \mathrm{HCl}\right)\end{array}$ & $\begin{array}{l}98.18 \\
0.24,0.26,0.29,0.42\end{array}$ \\
$\begin{array}{l}\text { Base hydrolysis }\left(80^{\circ} \mathrm{C}, 2 \mathrm{hrs}, 2 \mathrm{ml}, 1 \mathrm{~N}\right. \\
\mathrm{NaOH})\end{array}$ & 89.16 & $0.21,0.22,0.26,0.30$ \\
$\begin{array}{l}\text { Oxidation }\left(80^{\circ} \mathrm{C}, 1 \mathrm{~h}, 2 \mathrm{~mL}, 50 \% \text { Hydrogen }\right. \\
\text { peroxide) }\end{array}$ & 65.59 & $\begin{array}{l}0.23,0.29,0.40,0.52,0.59, \\
\text { Photolytic degradation }(\mathrm{UV} 254,4 \text { days })\end{array}$ \\
$\begin{array}{l}0.65 \\
\text { Thermal degradation }\left(105^{\circ} \mathrm{C}, 4 \text { days }\right)\end{array}$ & 99.95 & $\begin{array}{l}\text { No major degradation peak } \\
\text { observed } \\
\text { No major degradation peak } \\
\text { observed }\end{array}$ \\
\hline
\end{tabular}

\section{Precision}

The precision was determined at the LOQ concentration for etoricoxib, impurity-A, impurity-B and impurity and the \% RSD was found to be below 4.36 for all impurities.

\section{Limit of detection and limit of quantification}

The Values of LOD and LOQ for etoricoxib, impurity-A, impurity-B and impurity-C are mentioned in the Table 3 .

\section{Linearity}

Linearity calibration plot for the related substances method was obtained over the calibration ranges tested i.e. LOQ, $50 \%, 100 \%$ and $150 \%$ of the specification limit. The correlation coefficient obtained was greater than 0.99 . The above results show that an excellent correlation existed between the peak area and the concentration of all three impurities. 


\section{Accuracy}

The Accuracy of all these related substances was found to be in between the predefined acceptance criteria of 80 to $120 \%$ and the data given in Table 3 .

Table 3. Validation results summary

\begin{tabular}{ccccc}
\hline Parameter & Etoricoxib & Impurity-A & Impurity-B & Impurity-C \\
\hline $\mathrm{R}^{2}$ value & 0.9999 & 0.9936 & 0.9934 & 0.9997 \\
Response factor & 1.00 & 1.00 & 0.89 & 0.97 \\
LOD in $\mu \mathrm{g} / \mathrm{mL}$ & 0.0016 & 0.00022 & 0.0058 & 0.0022 \\
LOQ in $\mu \mathrm{g} / \mathrm{mL}$ & 0.003 & 0.004 & 0.008 & 0.013 \\
\%RSD at LOQ & 4.359 & 3.273 & 1.930 & 1.965 \\
Precision & 1.344 & 4.093 & 0.418 & 2.067 \\
Accuracy at LOQ & -- & 97.01 & 96.59 & 95.68 \\
Accuracy at 50\% & -- & 97.55 & 100.24 & 100.97 \\
Accuracy at $100 \%$ & -- & 97.20 & 99.60 & 99.00 \\
Accuracy at $150 \%$ & -- & 97.29 & 99.45 & 98.85 \\
\hline
\end{tabular}

\section{Robustness}

When the chromatographic conditions flow rate, mobile phase composition, $\mathrm{pH}$ were deliberately varied and resolution between any two peaks is greater than 2.0, which is illustrating the robustness of the method.

\section{Solution stability}

There were no significant changes in the amounts of the impurities during solution stability experiment performed using the related substances method. The results from the studies indicated, the sample solution was stable at room temperature for $48 \mathrm{~h}$.

\section{Conclusion}

A new, accurate and selective isocratic HPLC method was developed for the determination of related substances in etoricoxib drug substance and validated as per the ICH guidelines. The method was found to be simple, selective, precise, accurate and robust. Therefore, this method can be used for routine testing as well as stability analysis of Etoricoxib drug substance. All statistical result was within the acceptance criteria.

\section{Acknowledgment}

We acknowledge the support of the Vindhya group of companies for their many practical contributions in AR\&D. We thank Mr.D N Reddy, Managing Director for permitting this work to be published. The authors acknowledge the help rendered by Dr.B.Chandrasekhar and other colleagues for the technical support and useful discussion.

\section{References}

1. Daniel D S L, Richard F D O, Rejean F M N, Zhaoyin W P and Jacues Y G L, US Patent USP5816419, 1997.

2. Shunta D, Martina K S, Vesta and T L Ripley, Annal Pharmaco., 2005, 39, 854-862.

3. Donnely M T, Hawkey C J and Alim, Pharmacol Thera., 1997, 11, 227.

4. Jouzeav JY, Terlinin B and Abid A, NSAIDs Drugs, 1997, 53, 563.

5. Mitchell, Akarassereenant and Thiemermann, Proc Nat Acad Sci., 1994, 1, 90. 
6. Nageswara R, Rao S, Meena A and Raghuram Rao. J Pharma Biomed Anal, 2005, 39(3-4), 349-363.

7. Ramakrishna N V S, Vishwottam K N, Wishu S and Koteshwara S, J Chromatogr., 2005, 816, 215-221.

8. Patel H M, Suhagia B N, Shah S A and Rathod I S, Ind J Pharm Sci., 2007, 69(5), 703-705.

9. Dinesh N V and Arun A K, Eur J Anal Chem., 2007, 2(3), 151-158.

10. Mandal U, Senthil R D, Bose A, Gowdak K V, Ghosh A and Pal T K, Indian J Pharm Sci., 2006, 68, 485-489.

11. Maitreyi Z and Amit K, Int J Adv Pharm Sci., 2010, 1(2), 181-186.

12. Pattan S R, Jamdar S G, Godge R K, Dighe N S, Daithankar A V, Nirmal S A and Pai M G, J Chem Pharmaceu Res., 2009, 1, 329-335.

13. Syal P K, Sahoo M, Ingale K D, Ingale S S, Choudhari V P and Kuchekar B S, Der Pharma Chemia., 2010, 2(4), 93-102.

14. Likhar Amrutha D, Gupta K R and Wadodkar S G, Int J Pharm Pharmceu Sci., 2010, 2(1),156-161.

15. Kamal S, Alka G and Pradeep M, E-J Chem., 2009, 6(1), 207-212.

16. Shahi S R, Agrawal G R, Rathi P B, Shinde N V, Somani V G, Mahamuni S B and Padalkar A N, Rasayan J Chem., 2008, 1(2), 390-394.

17. International Conferences on Harmonization Q3A (R2): Draft Revised Guidance on impurities in New Drug Substances, 2006; http://www.ich.org

18. International Conferences on Harmonization Q2 (R1) Validation of Analytical Procedures: text and methodology, 2005; http://www.ich.org 


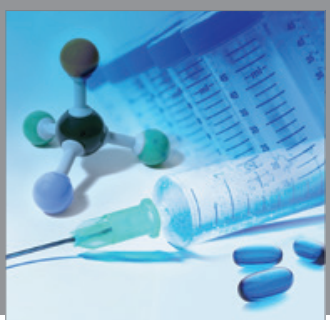

International Journal of

Medicinal Chemistry

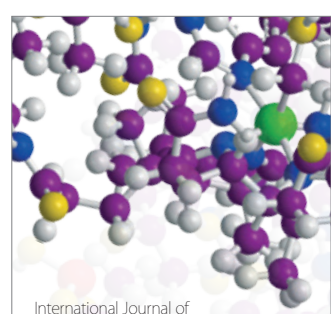

Carbohydrate Chemistry

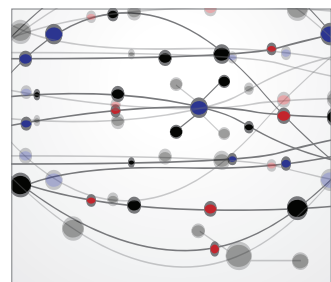

The Scientific World Journal
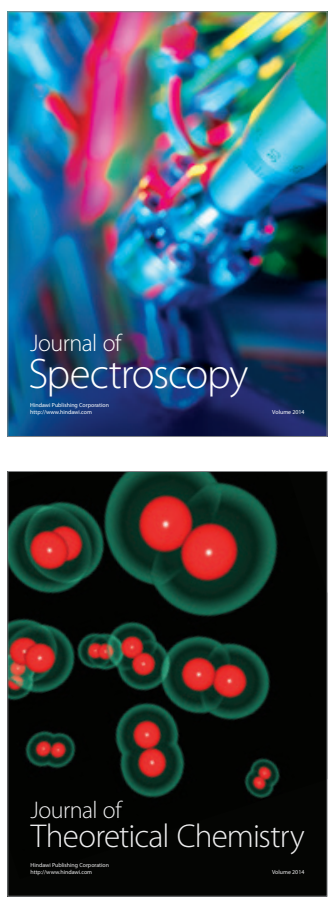
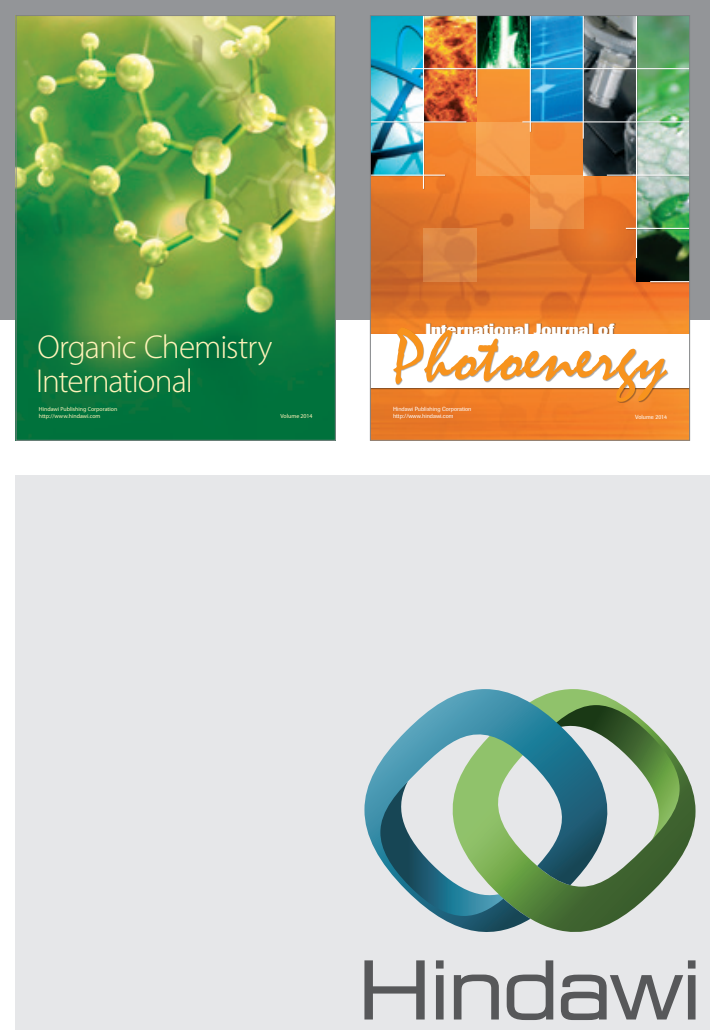

Submit your manuscripts at

http://www.hindawi.com
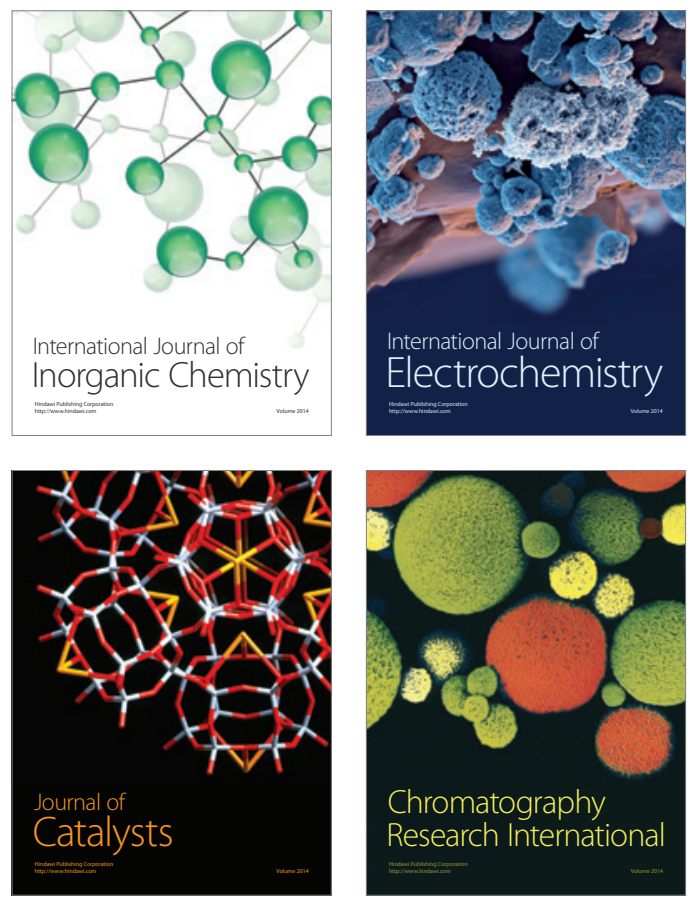
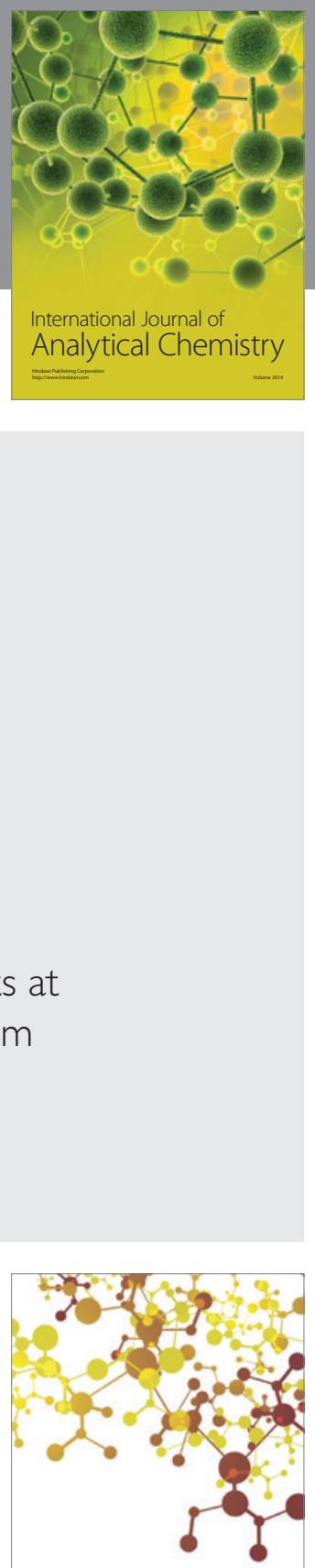

Journal of

Applied Chemistry
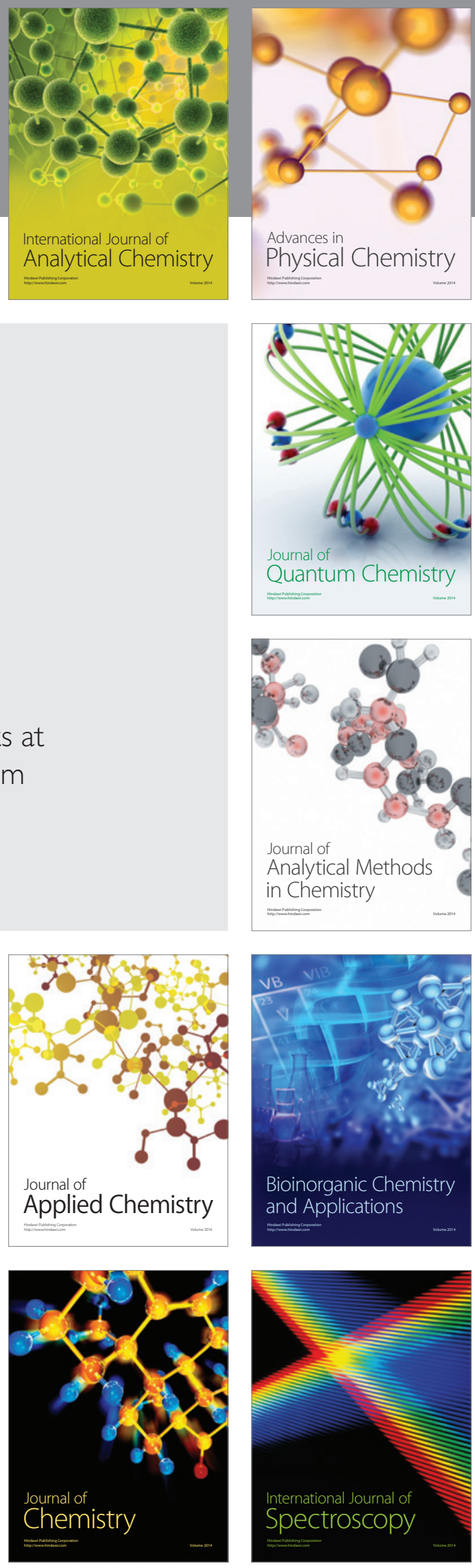